\title{
Bioreactance reliably detects preload responsiveness by the end-expiratory occlusion test when averaging and refresh times are shortened
}

Francesco Gavelli ${ }^{1} 2^{*} \mathbb{B}$, Alexandra Beurton ${ }^{1}$, Jean-Louis Teboul', Nello De Vita', Danila Azzolina ${ }^{3}$, Rui Shi', Arthur Pavot ${ }^{1}$ and Xavier Monnet ${ }^{1}$

\begin{abstract}
Background: The end-expiratory occlusion (EEXPO) test detects preload responsiveness, but it is $15 \mathrm{~s}$ long and induces small changes in cardiac index (CI). It is doubtful whether the Starling bioreactance device, which averages $\mathrm{Cl}$ over $24 \mathrm{~s}$ and refreshes the displayed value every $4 \mathrm{~s}$ (Starling-24.4), can detect the EEXPO-induced changes in $\mathrm{Cl}(\Delta \mathrm{Cl})$. Our primary goal was to test whether this Starling device version detects preload responsiveness through EEXPO. We also tested whether shortening the averaging and refresh times to $8 \mathrm{~s}$ and one second, respectively, (Starling-8.1) improves the accuracy of the device in detecting preload responsiveness using EEXPO.

Methods: In 42 mechanically ventilated patients, during a 15-s EEXPO, we measured $\triangle C$ l through calibrated pulse contour analysis ( $\mathrm{Cl}_{\text {pulse, }}$ PiCCO2 device) and using the Starling device. For the latter, we considered both $\mathrm{Cl}_{\text {Starling-24.4 }}$ from the commercial version and $\mathrm{Cl}_{\text {Starling-8.1 }}$ derived from the raw data. For relative $\Delta \mathrm{Cl}_{\text {Starling-24.4 }}$ and $\Delta \mathrm{Cl}_{\text {Starling-8.1 }}$ during EEXPO, we calculated the area under the receiver operating characteristic curve (AUROC) to detect preload responsiveness, defined as an increase in $\mathrm{Cl}_{\text {pulse }} \geq 10 \%$ during passive leg raising (PLR). For both methods, the correlation coefficient vs. $\Delta \mathrm{Cl}_{\text {pulse }}$ was calculated.

Results: Twenty-six patients were preload responders and sixteen non preload-responders. The AUROC for $\triangle \mathrm{Cl}_{\text {Star- }}$ ling-24.4 Was significantly lower compared to $\Delta \mathrm{Cl}_{\text {Starling-8.1 }}(0.680 \pm 0.086$ vs. $0.899 \pm 0.049$, respectively; $p=0.027)$. A significant correlation was observed between $\Delta \mathrm{Cl}_{\text {Starling-8.1 }}$ and $\Delta \mathrm{Cl}_{\text {pulse }}(r=0.42 ; p=0.009)$, but not between $\Delta \mathrm{Cl}_{\text {Starling-24.4 }}$ and $\Delta \mathrm{Cl}_{\text {pulse. }}$. During PLR, both $\Delta \mathrm{Cl}_{\text {Starling-24.4 }}$ and $\Delta \mathrm{Cl}_{\text {Starling-8.1 }}$ reliably detected preload responsiveness.
\end{abstract}

Conclusions: Shortening the averaging and refresh times of the bioreactance signal to $8 \mathrm{~s}$ and one second, respectively, increases the reliability of the Starling device in detection of EEXPO-induced $\triangle \mathrm{Cl}$.

Trial registration: No. IDRCB:2018-A02825-50. Registered 13 December 2018.

Keywords: Fluid, Cardiac index, Monitoring, Passive leg raising, Fluid challenge, Heart lung interactions

*Correspondence: francesco.gavelli@uniupo.it

${ }^{1}$ Service de Médecine Intensive-Réanimation, Université Paris-Saclay, AP-HP, Hôpital de Bicêtre, DMU CORREVE, Inserm UMR S_999, FHU SEPSIS,

CARMAS, 78, Rue du Général Leclerc, 94270 Le Kremlin-Bicêtre, France

Full list of author information is available at the end of the article original author(s) and the source, provide a link to the Creative Commons licence, and indicate if changes were made. The images or other third party material in this article are included in the article's Creative Commons licence, unless indicated otherwise in a credit line to the material. If material is not included in the article's Creative Commons licence and your intended use is not permitted by statutory regulation or exceeds the permitted use, you will need to obtain permission directly from the copyright holder. To view a copy of this licence, visit http://creativecommons.org/licenses/by/4.0/. 


\section{Background}

Over the last decade, much effort has been put into the development of methods monitoring cardiac index (CI) non-invasively [1-6]. Among them, bioreactance estimates cardiac output by analyzing the phase shift between an inward current that is sent through the thorax and the resulting outward current [1]. The principle of the technique is that this phase shift is determined by the variation of the volume of the thorax. From beat to beat, this variation is related to the variation of the volume of blood in the descending aorta and, thus, to stroke volume [7]. Bioreactance is considered as an improvement of bioimpedance which might be less sensitive to artifacts and the patient's movements. The technique is totally non-invasive, as it only requires electrodes pasted on the thorax.

It has been shown to detect real-time changes of CI $(\triangle \mathrm{CI})$ induced by a passive leg raising (PLR) test and volume expansion [7]. Besides the PLR test, the end-expiratory occlusion (EEXPO) test is another test assessing preload responsiveness which can be used in mechanically ventilated patients. It consists in interrupting mechanical ventilation at end-expiration for a few seconds, which increases cardiac preload, and in observing the $\Delta \mathrm{CI}$ which occurs in cases of preload responsiveness. Its accuracy has been established [12-14] and it is easy to perform.
Nevertheless, the duration of EEXPO is only $15 \mathrm{~s}$, and the induced $\triangle \mathrm{CI}$ are relatively small [12]. It is then uncertain whether the available commercial version of the bioreactance device, which averages the CI signal over $24 \mathrm{~s}$ and refreshes the displayed value every $4 \mathrm{~s}$, is adequate for monitoring the effects of EEXPO (Fig. 1). Thus, the primary goal of this study was to test whether the commercial version of the bioreactance device accurately detects preload responsiveness through the EEXPOinduced $\Delta \mathrm{CI}$. The secondary goal was to assess whether shortening the averaging and refresh times of the device improves this detection. We hypothesized that bioreactance can monitor the EEXPO effects on $\mathrm{CI}$, provided that the time over which it averages $\mathrm{CI}$ and after which it refreshes its displayed value is short.

\section{Patients and methods}

\section{Patients}

This prospective study was conducted in a 25-bed intensive care unit (ICU) and approved by an Institutional Review Board (No. IDRCB: 2018-A02825-50). At the time of inclusion, patients' next of kin were informed of the study protocol and of the option to refuse participation. As soon as clinical conditions improved and patients were able to give consent, the same opportunity was given to them. All patients and/ or relatives agreed to participate.

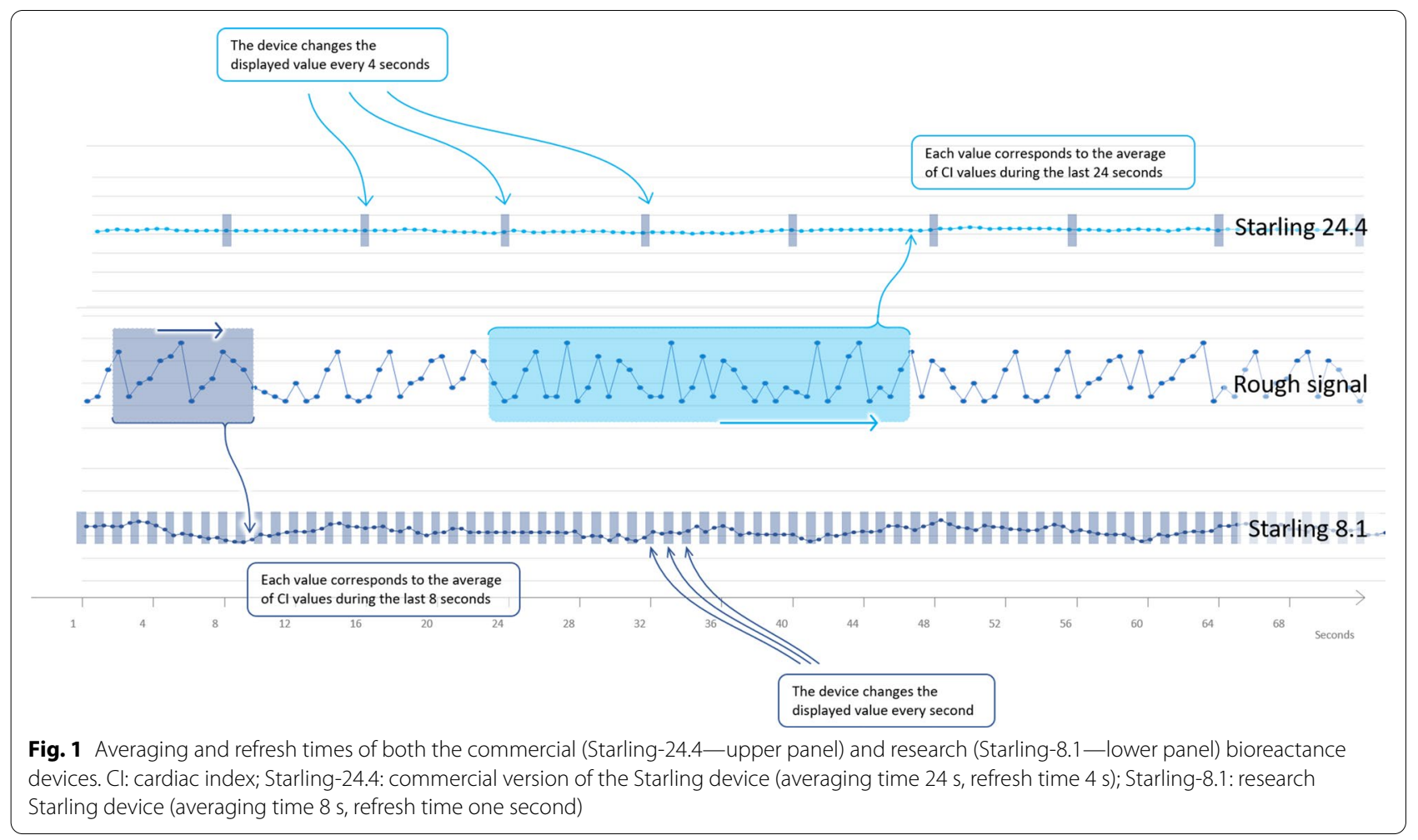


Patients were included if they met the following inclusion criteria: age $\geq 18$ years, admission to the ICU for less than $24 \mathrm{~h}$, invasive mechanical ventilation, $\mathrm{PiCCO} 2$ device already in place (Pulsion Medical Systems, Feldkirchen, Germany) and decision by the attending clinicians to perform a PLR test. Exclusion criteria were intra-abdominal hypertension and venous compression stockings (which may decrease the PLR test reliability) [15], intracranial hypertension (which is a contraindication for PLR) and inability of the patients to sustain a 15-s EEXPO. Patients were included depending on the availability of the investigators. The study report complies with the Standards for Reporting Diagnostic Accuracy (STARD) statement [16].

\section{Bioreactance measurements}

The Starling v5.5 device (Baxter, Deerfield, IL, USA) requires 4 double-electrode sensors pasted on the thorax skin, creating a "virtual box" around the heart. The upper sensors are placed on the mid-right and midleft clavicles and the lower sensors on the mid-right and mid-left last ribs. In each electrode pair, the outer one delivers a current with known alternating high frequency, detected by the inner electrode pair. The phase modulation between currents recorded at the inner and outer electrodes is altered by the changes in thoracic pulsatile blood volume, which allows a proprietary algorithm to derive stroke volume and CI $[1,17,18]$.

The Starling v5.5 device displays a CI value which corresponds to the moving average of the raw values that have been measured over the last $24 \mathrm{~s}$ (Fig. 1). The displayed average is refreshed on the screen every $4 \mathrm{~s}$. The CI value measured in this way will hereafter be called " $\mathrm{CI}_{\text {Starling-24.4" }}$

We also extracted raw data from our recordings by the Starling device. In a post-hoc analysis, we changed the averaging time to $8 \mathrm{~s}$, instead of 24 . This duration was the shortest possible time that could be achieved, according to the technological limitations of the currently available device. We judged this interval as appropriate for estimating the effects of the 15-s EEXPO.

The refreshing delay was reduced to one second, instead of 4 . The CI value obtained in this way will be called "CI $\mathrm{C}_{\text {Starling 8.1 }}$ " (Fig. 1).

\section{Transpulmonary thermodilution and pulse contour analysis measurements}

The PiCCO2 device measures $\mathrm{CI}$ through transpulmonary thermodilution, which is performed by injecting three $15-\mathrm{mL}$ boluses of cold saline in the superior vena cava $[19,20]$, and through pulse contour analysis $\left(\mathrm{CI}_{\text {pulse }}\right)$, which is calibrated by transpulmonary thermodilution [21]. The value of $\mathrm{CI}_{\text {pulse }}$ provided by pulse contour analysis is averaged over $12 \mathrm{~s}$, with values that are refreshed every second. $\mathrm{CI}_{\text {pulse }}$ was continuously recorded by the PiCCOWin software (Pulsion Medical Systems).

\section{Other measurements}

In addition to arterial pressure, heart rate and CI, we measured central venous pressure at end-expiration. Respiratory variables such as positive end-expiratory pressure, plateau pressure, respiratory rate and tidal volume (Vt) were also collected. Intra-abdominal pressure was measured through the bladder pressure as previously described [22].

Arterial, central venous and airway pressures were continuously recorded by data acquisition software (HEM3.5, Notocord, Croissy-sur-Seine, France).

\section{Study protocol}

At baseline, a set of thermodilution measurements was performed and $\mathrm{CI}_{\text {pulse }}$ was calibrated. Once hemodynamic stability was observed (change in mean arterial pressure $<5 \%$ over $4 \mathrm{~min})\left(\mathrm{EEXPO}_{\text {start }}\right), \mathrm{CI}_{\text {pulse }}$, $\mathrm{CI}_{\text {Starling-24.4 }}, \mathrm{CI}_{\text {Starling-8.1 }}$ and other hemodynamic measurements were collected. A 15-s EEXPO was then initiated as previously described [12]. At the end of the EEXPO test $\left(\mathrm{EEXPO}_{\text {end }}\right)$, the same variables were recorded. Subsequently, once the values of the hemodynamic variables had returned to baseline, another set of measurements were performed $\left(\mathrm{PLR}_{\text {start }}\right)$. A PLR maneuver was performed as previously described [23], and, after $1 \mathrm{~min}$ of PLR, measurements were collected again $\left(P L R_{\text {end }}\right)$. If the $\Delta C I_{\text {pulse }}$ between $P L R_{\text {start }}$ and $\operatorname{PLR}_{\text {end }}$ was $\geq 10 \%$, the patient was defined as a "preload responder". This threshold corresponds to the increase in CI that has been demonstrated to indicate preload responsiveness with the best combination of sensitivity and specificity [24]. Sedative drugs, catecholamines and ventilatory settings were kept unchanged during the study period.

\section{Statistical analysis}

Based on a previous study by our group [11], to detect an increase in CI of at least $5 \%$ measured by the Starling device, expecting a baseline value of $3.1 \mathrm{~L} / \mathrm{min} / \mathrm{m}^{2}$, we estimated that 42 pairs of measurements were required. This assessment was performed taking into account an $\alpha$ risk of $5 \%$ and a $\beta$ risk of $20 \%$, estimating that half of the patients would be preload responders. The minimal change of $5 \%$ was chosen, because it corresponds to the best threshold of EEXPO-induced $\mathrm{CI}$ changes that 
detects preload responsiveness [14]. It is compatible with the least significant change of $\mathrm{CI}_{\text {pulse }}$ [25].

Data are summarized as mean $\pm \mathrm{SD}$ or median [interquartile range, IQR] as appropriate. The normality of distribution was evaluated visually. Pairwise comparisons of data were done with the paired Student's $t$ test or Wilcoxon test. The two-tailed Student's $t$ test or Mann-Whitney $U$ test compared preload responders and non-responders.

To assess the significance of changes of variables over time during different interventions, we used a linear mixed-effect model to evaluate the group (preload responders and non-responders) and time (EEXPO $E_{E X P O}$ end $, P^{2} R_{\text {start }}, P R_{\text {end }}$ ) effects on hemodynamic variables. Time and groups were assumed as fixed effects, also considering the interaction component. A random intercept term was considered in patients to account for correlation among repeated measurements. The posthoc pairwise comparison was reported by adjusting $p$ values for multiple testing, using the Holm method [26]. Regarding our primary goal, receiver operating characteristic curves for EEXPO-induced relative $\Delta \mathrm{CI}_{\text {Starling-24.4 }}$ to predict preload responsiveness were built, providing sensitivity, specificity and the best threshold, and their area under the receiver operating characteristic curve (AUROC) was measured. The same analysis was performed for $\Delta \mathrm{CI}_{\text {Starling-8.1 }}$ to assess our secondary goal, and the AUROC were compared with the Hanley-McNeil test [27]. The ability of both $\Delta \mathrm{CI}_{\text {Starling-24.4 }}$ and $\Delta \mathrm{CI}_{\text {Star- }}$ ling-8.1 to detect preload responsiveness was subsequently tested in the subgroup of patients with and without norepinephrine infusion and in patients with a high and a low body mass index (BMI). "High" and "low" BMI values were defined according to the median of the variable measured in the whole population. To evaluate the overall concordance between absolute values of $\mathrm{CI}_{\text {pulse }}$ and both $\mathrm{CI}_{\text {Starling 24.4 }}$ and $\mathrm{CI}_{\text {Starling 8.1 }}$ for EEXPO, we reported the intraclass correlation coefficient (ICC). Pearson's correlation coefficient tested the correlations between the EEXPO-induced $\Delta \mathrm{CI}_{\text {pulse }}$ and both $\Delta \mathrm{CI}_{\text {Starling-24.4 }}$ and $\Delta \mathrm{CI}_{\text {Starling-8.1 }}$, and these coefficients were compared for relative changes.

We compared the absolute values of $\mathrm{CI}_{\text {pulse }}$ and $\mathrm{CI}_{\text {Starling-24.4 }}$ and the absolute values of $\mathrm{CI}_{\text {pulse }}$ and $\mathrm{CI}_{\text {Starling-8.1 }}$ recorded during EEXPO $\mathrm{Etart}_{\text {, }} \mathrm{EEXPO}_{\text {end }}$, $\mathrm{PLR}_{\text {start }}$ and $P L R_{\text {end }}$ using the Bland-Altman analysis. Limits of agreement plots were defined as accounting for repeated measurements with possibly heteroscedastic measurement errors [28]. A Critchley polar plot analysis was performed [29] for assessment of the trending ability of $\mathrm{CI}_{\text {Starling-24.4 }}$ and $\mathrm{CI}_{\text {Starling-8.1. }}$, to compare the concordance in terms of relative $\Delta \mathrm{CI}_{\text {pulse }} \nu s$. $\Delta \mathrm{CI}_{\text {Starling-24.4 }}$ and $\Delta \mathrm{CI}_{\text {Starling-8.1 }}$, both for EEXPO and PLR. Radial limits of agreement $<30^{\circ}$ are considered to indicate good trending ability.

Statistical significance was set at a $p$ value $<0.05$ and statistical analysis was performed with MedCalc software 19.1 (Mariakerke, Belgium) and R 3.5.2 statistical software with lme4, MethodCompare and irr packages [30].

\section{Results}

\section{Patients}

Forty-two patients were included between April and September 2019. No patient was excluded due to inability to sustain a 15-s respiratory hold (Additional file 1: Figure S1). All patients were sedated with propofol and remifentanil (Table 1). Eight (19\%) patients were paralyzed at the time of inclusion and no patient exhibited spontaneous breathing activity. No patient was in the prone position or had renal replacement therapy in place. Two patients had atrial fibrillation, whereas the others were in sinus rhythm (Table 1).

\section{Hemodynamic changes during interventions}

Twenty-six (62\%) patients were defined as preload responders, according to the results of the PLR test. The

Table 1 Patient characteristics

\begin{tabular}{|c|c|}
\hline \multicolumn{2}{|l|}{ Patient characteristics $(n=42)$} \\
\hline Age (years) & $60 \pm 9$ \\
\hline Male gender (n, \%) & $21(50 \%)$ \\
\hline Body mass index $\left(\mathrm{kg} / \mathrm{m}^{2}\right)$ & $24[21-27]$ \\
\hline Simplified Acute Physiologic Score II on inclusion & $49[31-55]$ \\
\hline Richmond Agitation Sedation Scale score & $-5[-5$ to -4$]$ \\
\hline Left ventricular ejection fraction (\%) & $45 \pm 6$ \\
\hline Intra-abdominal pressure (mmHg) & $13 \pm 4$ \\
\hline \multicolumn{2}{|l|}{ Type of shock $(n, \%)$} \\
\hline $\begin{array}{l}\text { Septic } \\
\text { Cardiogenic } \\
\text { Hypovolemic } \\
\text { Distributive non-septic }\end{array}$ & $\begin{array}{l}36(85.7 \%) \\
4(9.5 \%) \\
1(2.4 \%) \\
1(2.4 \%)\end{array}$ \\
\hline Atrial fibrillation $(n, \%)$ & $2(4.8 \%)$ \\
\hline Cumulative fluid balance (mL) & 1035 [734-1655] \\
\hline ICU length of stay (days) & $17[7-44]$ \\
\hline Mortality at day-28 (n, \%) & $13(31 \%)$ \\
\hline \multicolumn{2}{|l|}{ Norepinephrine } \\
\hline $\begin{array}{l}\text { Number of patients (\%) } \\
\text { Dose of norepinephrine ( } \mathrm{gg} / \mathrm{kg} / \mathrm{min})\end{array}$ & $\begin{array}{l}27(64 \%) \\
0.28[0.13-0.43]\end{array}$ \\
\hline \multicolumn{2}{|l|}{ Ventilator settings } \\
\hline $\begin{array}{l}\text { Tidal volume }(\mathrm{mL} / \mathrm{kg} \text { of PBW) } \\
\text { Respiratory rate }(\text { breaths } / \mathrm{min}) \\
\text { Fraction of inspired oxygen } \\
\text { Positive end-expiratory pressure }\left(\mathrm{cmH}_{2} \mathrm{O}\right) \\
\text { Plateau pressure }\left(\mathrm{cmH}_{2} \mathrm{O}\right)\end{array}$ & $\begin{array}{l}6.0[5.1-6.0] \\
28 \pm 5 \\
0.51 \pm 0.16 \\
12 \pm 3 \\
25 \pm 5\end{array}$ \\
\hline
\end{tabular}

ICU intensive care unit, $P B W$ predicted body weight 
changes in hemodynamic variables in both groups are shown in Table 2.

PLR induced a $\Delta \mathrm{CI}_{\text {pulse }}$ of $16.8[12.0-24.43 \%]$ in responders and 2.2 [1.3-4.5\%] in non-responders $(p<0.0001)$. It induced a $\Delta \mathrm{CI}_{\text {Starling-24.4 }}$ of 21.7 [14.3$43.8 \%]$ in responders and 0.0 [0.0-4.1\%] in non-responders $(p<0.0001)$. PLR induced a $\Delta \mathrm{CI}_{\text {Starling-8.1 }}$ of 49.7 [29.3-74.4\%] in responders and $5.1[-0.4-11.1 \%]$ in nonresponders $(p<0.0001)$ (Table 2$)$.

The EEXPO test induced a $\Delta \mathrm{CI}_{\text {pulse }}$ of $5.3[4.1-7.5 \%]$ in responders and $1.2[0.5-2.4 \%]$ in non-responders $(p<0.0001)$. It induced a $\Delta \mathrm{CI}_{\text {Starling-24.4 }}$ of $5.5[-0.2-7.1 \%]$ in responders and $0.1[-0.1-0.1 \%]$ in non-responders $(p=0.049)$. The EEXPO test induced a $\Delta \mathrm{CI}_{\text {Starling-8.1 }}$ of
12.8 [7.8-22.2\%] in responders and $0.9[-1.1-4.8 \%]$ in non-responders $(p=0.0001)$ (Table 2$)$.

\section{Ability of the EEXPO-induced $\Delta \mathrm{Cl}_{\text {Starling-24.4 }}$ to detect preload responsiveness}

The relative EEXPO-induced $\Delta \mathrm{CI}_{\text {pulse }}$ detected preload responsiveness, as defined by a positive PLR test, with an AUROC of $0.983 \pm 0.018$. The cut-off corresponding to the best Youden index was 3.3\% (Table 3).

The relative EEXPO-induced $\Delta \mathrm{CI}_{\text {Starling-24.4 }}$ detected preload responsiveness with an AUROC of $0.680 \pm 0.086$ and a best Youden index cut-off of $0.1 \%$ (Fig. 2, Table 3).

Table 2 Hemodynamic measurements

\begin{tabular}{|c|c|c|c|c|}
\hline Variables & EEXPO $_{\text {start }}$ & $\mathrm{EEXPO}_{\text {end }}$ & $\mathrm{PLR}_{\text {start }}$ & $\mathrm{PLR}_{\text {end }}$ \\
\hline \multicolumn{5}{|l|}{ Heart rate $\left(\mathrm{min}^{-1}\right)$} \\
\hline Preload responders $(n=26)$ & $95 \pm 16$ & $96 \pm 17$ & $96 \pm 17$ & $93 \pm 18^{* *}$ \\
\hline Preload non-responders $(n=16)$ & $93 \pm 23$ & $93 \pm 23$ & $93 \pm 22$ & $93 \pm 22$ \\
\hline \multicolumn{5}{|l|}{ Systolic arterial pressure $(\mathrm{mmHg})$} \\
\hline Preload responders $(n=26)$ & $120 \pm 17$ & $121 \pm 17$ & $122 \pm 20$ & $136 \pm 16^{* *}$ \\
\hline Preload non-responders $(n=16)$ & $134 \pm 24^{\mathrm{a}}$ & $134 \pm 24^{\mathrm{a}}$ & $132 \pm 18$ & $139 \pm 18$ \\
\hline \multicolumn{5}{|l|}{ Diastolic arterial pressure $(\mathrm{mmHg})$} \\
\hline Preload responders $(n=26)$ & $60 \pm 11$ & $60 \pm 10$ & $62 \pm 11$ & $67 \pm 11^{* *}$ \\
\hline Preload non-responders $(n=16)$ & $68 \pm 11^{a}$ & $68 \pm 11^{a}$ & $67 \pm 11$ & $71 \pm 9$ \\
\hline \multicolumn{5}{|l|}{ Mean arterial pressure $(\mathrm{mmHg})$} \\
\hline Preload responders $(n=26)$ & $82 \pm 12$ & $82 \pm 11$ & $83 \pm 13$ & $93 \pm 12^{* *}$ \\
\hline Preload non-responders $(n=16)$ & $92 \pm 12^{\mathrm{a}}$ & $92 \pm 13^{\mathrm{a}}$ & $91 \pm 11^{\mathrm{a}}$ & $96 \pm 9$ \\
\hline \multicolumn{5}{|l|}{ Central venous pressure (mmHg) } \\
\hline Preload responders $(n=26)$ & $11 \pm 5$ & $11 \pm 4$ & $12 \pm 4$ & $14 \pm 5^{* *}$ \\
\hline Preload non-responders $(n=16)$ & $14 \pm 4^{\mathrm{a}}$ & $13 \pm 4$ & $14 \pm 4$ & $15 \pm 3$ \\
\hline \multicolumn{5}{|l|}{ PiCCO2 Cardiac Index (L/min/m²) } \\
\hline Preload responders $(n=26)$ & $2.95 \pm 1.05$ & $3.12 \pm 1.06^{*}$ & $2.89 \pm 0.94$ & $3.40 \pm 1.03^{* *}$ \\
\hline Preload non-responders $(n=16)$ & $3.03 \pm 0.87$ & $3.08 \pm 0.89$ & $2.97 \pm 0.78$ & $3.08 \pm 0.89$ \\
\hline \multicolumn{5}{|l|}{ Starling-24.4 Cardiac Index ( $\left(\mathrm{L} / \mathrm{min} / \mathrm{m}^{2}\right)$} \\
\hline Preload responders $(n=26)$ & $2.8 \pm 0.5$ & $3.0 \pm 0.6^{*}$ & $2.8 \pm 0.5$ & $3.5 \pm 0.7^{* *}$ \\
\hline Preload non-responders $(n=16)$ & $2.4 \pm 0.4^{\mathrm{a}}$ & $2.3 \pm 0.4^{\mathrm{a}}$ & $2.6 \pm 0.5$ & $2.6 \pm 0.5^{\mathrm{a}}$ \\
\hline \multicolumn{5}{|l|}{ Starling-8.1 Cardiac Index (L/min/m²) } \\
\hline Preload responders $(n=26)$ & $2.83 \pm 0.58$ & $3.25 \pm 0.71^{*}$ & $2.69 \pm 0.55$ & $3.98 \pm 0.86^{* *}$ \\
\hline Preload non-responders $(n=16)$ & $2.45 \pm 0.41$ & $2.48 \pm 0.39^{\mathrm{a}}$ & $2.63 \pm 0.50$ & $2.79 \pm 0.51^{a}$ \\
\hline \multicolumn{5}{|l|}{ Pulse pressure variation (\%) } \\
\hline Preload responders $(n=26)$ & $10 \pm 6$ & - & $11 \pm 7$ & $10 \pm 6$ \\
\hline Preload non-responders $(n=16)$ & $10 \pm 9$ & - & $11 \pm 8$ & $10 \pm 9$ \\
\hline \multicolumn{5}{|l|}{ Stroke volume variation (\%) } \\
\hline Preload responders $(n=26)$ & $12 \pm 6$ & - & $12 \pm 6$ & $11 \pm 6$ \\
\hline Preload non-responders $(n=16)$ & $11 \pm 8$ & - & $11 \pm 8$ & $11 \pm 8$ \\
\hline
\end{tabular}

${ }^{a} p<0.05$ vs. Preload responders

${ }^{*} p<0.05$ vs. EEXPO start $^{* *} p<0.05$ vs. PLR start 
Table 3 Ability of the end-expiratory occlusion test to detect preload responsiveness using three different methods for measuring cardiac index

\begin{tabular}{lllllrrr}
\hline Variable & AUROC \pm SE & Sensitivity (95\% Cl) & Specificity (95\% Cl) & LR $+\mathbf{( 9 5 \% ~ C l ) ~}$ & LR- (95\% Cl) & Cutoff & $\boldsymbol{p}$ \\
\hline EEXPO-Relative $\Delta \mathrm{Cl}_{\text {pulse }}$ & $0.983 \pm 0.018$ & $1.00(0.87-1.00)$ & $0.94(0.70-1.00)$ & $16.0(2.4-106.7)$ & - & $3.3 \%$ & $<0.0001$ \\
EEXPO-Relative $\Delta \mathrm{Cl}_{\text {Starling-24.4 }}$ & $0.680 \pm 0.086$ & $0.62(0.41-0.80)$ & $0.94(0.70-1.00)$ & $9.9(1.4-67.3)$ & $0.4(0.2-0.7)$ & $0.1 \%$ & 0.036 \\
EEXPO-Relative $\Delta \mathrm{Cl}_{\text {Starling-8.1 }}$ & $0.899 \pm 0.049$ & $0.79(0.59-0.93)$ & $0.86(0.57-0.98)$ & $5.54(1.5-20.3)$ & $0.24(0.1-0.5)$ & $5.1 \%$ & $<0.0001$
\end{tabular}

$A U R O C$ area under the receiver operating characteristic curve, EEXPO end-expiratory occlusion, $L R+$ positive likelihood ratio, $L R-$ negative likelihood ratio, $P L R$ passive leg raising; $S E$ standard error, $95 \% \mathrm{Cl} 95 \%$ confidence interval, $\triangle C_{\text {pulse }}$ changes in cardiac index measured through the pulse contour analysis method, $\Delta \mathrm{Cl}_{\text {Starling-24.4 }}$ changes in cardiac index detected by the commercial version of the Starling device (averaging time $24 \mathrm{~s}$, refresh time $4 \mathrm{~s}$ ), $\Delta \mathrm{Cl}_{\text {Starling-8.1 }} \mathrm{Changes}$ in cardiac index derived through raw data analysis of the Starling device (averaging time $8 \mathrm{~s}$, refresh time $1 \mathrm{~s}$ )

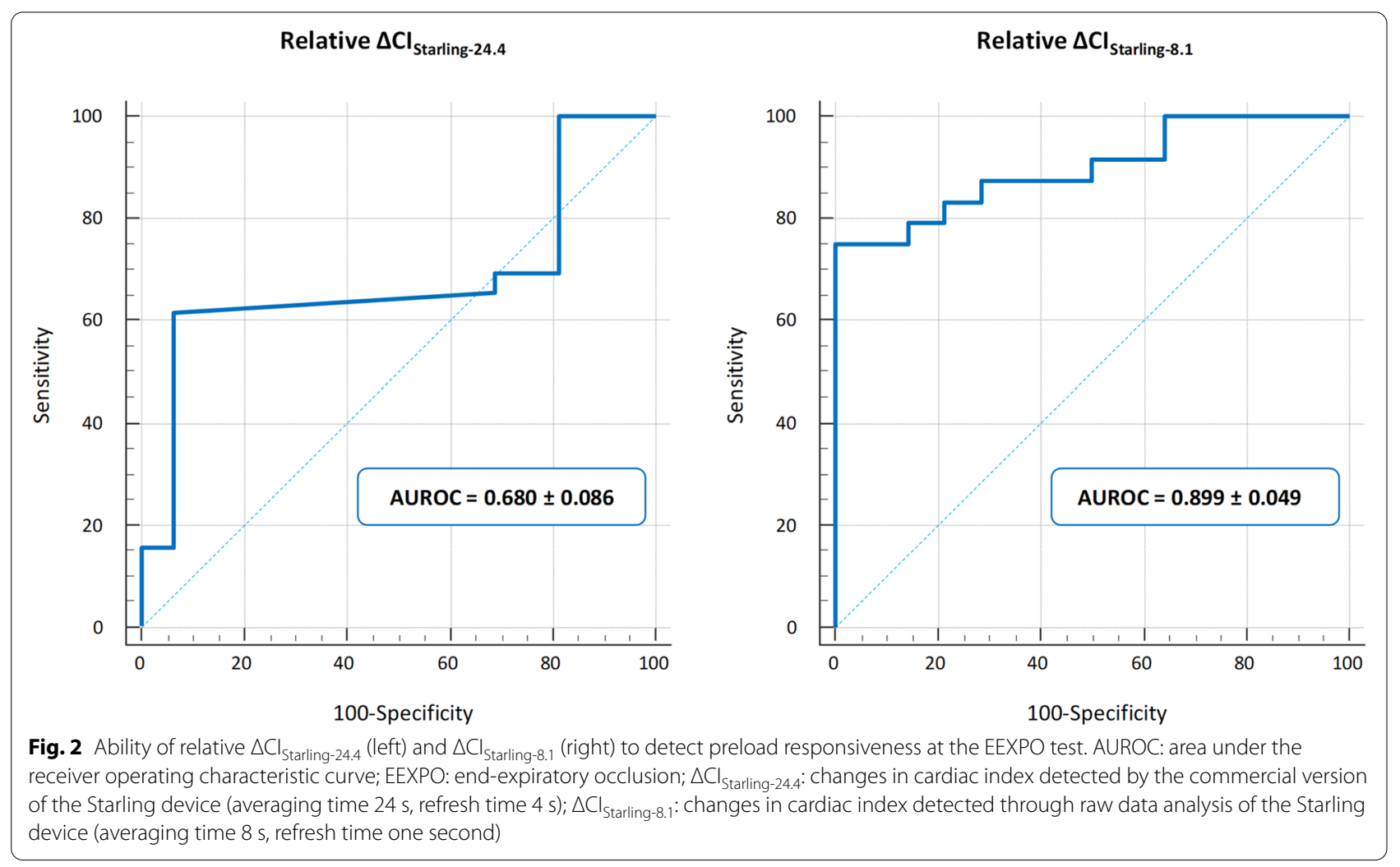

\section{Ability of the EEXPO-induced $\Delta \mathrm{Cl}_{\text {Starling-8.1 }}$ to detect preload responsiveness}

Relative EEXPO-induced $\Delta \mathrm{CI}_{\text {Starling-8.1 }}$ detected preload responsiveness with an AUROC of $0.899 \pm 0.049$ and a cut-off of $5.1 \%$ (Fig. 2, Table 3). The comparison with the AUROC of the EEXPO-induced $\Delta \mathrm{CI}_{\text {Starling-24.4 }}$ was significant $(p=0.027)$. At the EEXPO test, Starling-24.4 classified 10 patients as false negative and one as false positive, while Starling-8.1 classified 3 patients as false negative and 2 as false positive. When the same analysis was performed both in patients with and without norepinephrine infusion and in patients with high and low BMI, we observed similar results (Additional file 1: Tables S1 and S2).

\section{Ability of the PLR-induced $\Delta \mathrm{Cl}_{\text {Starling-24.4 }}$ and $\Delta \mathrm{Cl}_{\text {Starling-8.1 }}$ to detect preload responsiveness}

Relative PLR-induced $\quad \Delta \mathrm{CI}_{\text {Starling-24.4 }}$ detected preload responsiveness, as defined by the increase in $\Delta \mathrm{CI}_{\text {pulse }} \geq 10 \%$ during PLR, with an AUROC of $0.929 \pm 0.039$. The cut-off corresponding to the best Youden index was $10 \%$. Similarly, PLR-induced relative $\Delta \mathrm{CI}_{\text {Starling-8.1 }}$ detected preload responsiveness with an AUROC of $0.970 \pm 0.024$ and a best Youden index cut-off of $15 \%$ (Additional file 1: Table S3).

\section{Concordance analysis}

When considering all the changes observed during the study $(\mathrm{n}=84)$ at Bland-Altman analysis, absolute values 
of both $\mathrm{CI}_{\text {Starling-24.4 }}$ and $\mathrm{CI}_{\text {Starling-8.1 }}$ showed a regressive pattern vs. $\mathrm{CI}_{\text {pulse }}$, with the bias line moving for higher values (Additional file 1: Figure S2). The percentage error was $67 \%$ for $\mathrm{CI}_{\text {Starling-24.4 }}$ and $65 \%$ for $\mathrm{CI}_{\text {Starling-8.1 }}$.

The ICC for absolute value comparison $v s$. $\mathrm{CI}_{\text {pulse }}$ at the EEXPO test $(\mathrm{n}=42)$ was higher for $\mathrm{CI}_{\text {Starling-8.1 }}$ than for $\mathrm{CI}_{\text {Starling-24.4 }}(0.60$ vs. 0.48 , respectively; $p=0.04$ ). Again, when considering only the changes observed during EEXPO, a significant correlation was observed between relative $\Delta \mathrm{CI}_{\text {pulse }}$ and $\Delta \mathrm{CI}_{\text {Starling-8.1 }}(r=0.42 ; p=0.009)$, but not between $\Delta \mathrm{CI}_{\text {pulse }}$ and $\Delta \mathrm{CI}_{\text {Starling-24.4 }}(p=0.40)$. When considering only the changes observed during PLR, a significant correlation was observed both between $\Delta \mathrm{CI}_{\text {pulse }}$ and $\Delta \mathrm{CI}_{\text {Starling-8.1. }}$ and between $\Delta \mathrm{CI}_{\text {pulse }}$ and $\Delta \mathrm{CI}_{\text {Starling-24.4 }}$ ( $r=0.70$ and $r=0.60$, respectively; $p<0.0001$ for both).

When considering only the changes observed during $\operatorname{EEXPO~}(n=42)$ at polar plot analysis, after removing from the central exclusion data points for which $\Delta \mathrm{CI}$ were less than $1.5 \%$ [25], the ability to track $\Delta \mathrm{CI}$ was higher for $\mathrm{CI}_{\text {Starling-8.1 }}$ (polar concordance: $83 \%$ ) than for $\mathrm{CI}_{\text {Starling-24.4 }}$ (polar concordance: 71\%) (Fig. 3). When considering only the changes observed during PLR $(n=42)$, the ability to track $\Delta \mathrm{CI}$ was similar for $\mathrm{CI}_{\text {Starling-8.1 }}$ (polar concordance: $81 \%$ ) and for $\mathrm{CI}_{\text {Starling-24.4 }}$ (polar concordance: $86 \%$ ) (Additional file 1: Figure S3).

\section{Discussion}

This study shows that the commercial version of the Starling device poorly detects preload responsiveness through the EEXPO test. However, when the hemodynamic effects of the EEXPO test are tracked with a modified version of the Starling device, where the averaging time is reduced to $8 \mathrm{~s}$ and the refresh time to one second, the ability to detect preload responsiveness is good. In addition, this study confirms that bioreactance reliably follows the PLR-induced $\Delta C I$, whichever setting is used.

Over the years, different tests have been developed to detect preload responsiveness before deciding to infuse fluids or not [31]. However, these tests differ not only in the amplitude of $\Delta C I$ they induce, but also in the time over which these changes occur $[13,32]$. In particular, the EEXPO test was performed over 12 to $30 \mathrm{~s}$ in the studies that tested its reliability [33, 34].

Regarding the different techniques estimating $\mathrm{CI}$, the issue of averaging and refresh times is often neglected. Averaging the beat-to-beat values of $\mathrm{CI}$ allows the smoothing of $\mathrm{CI}$ changes, due either to its physiological instability or to the lack of precision of the technique that estimates it. Without any average, it would be difficult to distinguish small changes from the noise of the signal. Conversely, if the averaging period is very long, the signal could be so smoothed that small changes would be undetectable. Besides the averaging time, the frequency

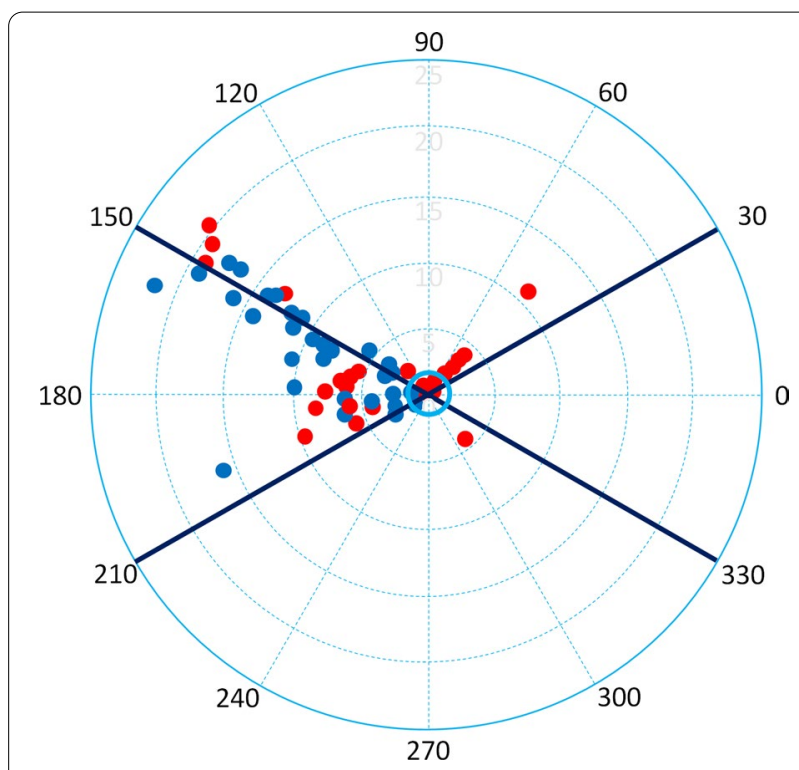

Fig. 3 Polar plot analysis during the EEXPO test. Polar plot analysis for relative changes in $\mathrm{Cl}_{\text {Starling-24.4 }}$ (red dots) and $\mathrm{Cl}_{\text {Starling-8.1 }}$ (blue dots) compared to the changes in $\mathrm{Cl}_{\text {pulse }}$ during the EEXPO test. The radial limits of the agreement have been reported. The central exclusion zone (continuous light blue circle) removes data points, where the changes in cardiac index are small (less than 1.5\%).

The polar concordance at 30 degrees is $83 \%$ for Starling-8.1.1 and 71\% for Starling-24.4. Cl pulse: cardiac index measured by the pulse contour analysis method; $\mathrm{Cl}_{\text {Starling-24.4: }}$ cardiac index measured by the commercial version of the Starling device (averaging time $24 \mathrm{~s}$, refresh time $4 \mathrm{~s}$ ); $\mathrm{Cl}_{\text {Starling-8.1. }}$ : cardiac index derived through raw data analysis of the Starling device (averaging time $8 \mathrm{~s}$, refresh time one second); EEXPO: end-expiratory occlusion

at which every new $\mathrm{CI}$ value is displayed is also crucial. If the value is refreshed at each cardiac beat, the displayed value may be very unstable, again impairing the assessment of significant changes. Conversely, in the event of infrequent refreshments, acute changes may be masked.

Our team has demonstrated that bioreactance did not reliably detect $\Delta C I$ induced by a 1-min PLR if the averaging time was $30 \mathrm{~s}$ [10]. A version of the NICOM device using a moving averaging period of $8 \mathrm{~s}$ was much better for this purpose [11]. In the present study, we investigated the ability of bioreactance to assess the EEXPO test, the duration of which is much shorter than that of the PLR test. For this purpose, we changed the averaging time and the refresh time from the raw values of CI estimated by bioreactance.

Regarding our primary goal, the EEXPO test was unable to detect preload responsiveness if assessed with the commercial version of the Starling device, which should not be used for this purpose. As a matter of fact, 11 (26\%) patients were wrongly classified by Starling-24.4 at the EEXPO test. Regarding our secondary goal, we confirmed that the EEXPO test was correctly assessed if the 
averaging and refresh times were reduced to 8 and one seconds, respectively. In the overall population, all but 5 patients were correctly defined as "preload responders" and "preload non-responders" by the Starling-8.1 device. However, among 2 of the 3 false negatives, the $\Delta \mathrm{CI}_{\text {Starling-8.1 }}$ was close to the $5 \%$ cut-off value (respectively, $4.7 \%$ and $4.8 \%$ ). This was also the case in one of the 2 false positives (5.7\%). Our results suggest that bioreactance can be used to perform the EEXPO test only if the averaging and refresh times of the device are shortened, at least transiently.

Our Bland-Altman and concordance analyses showed that the estimation of the absolute value of CI by bioreactance was far from perfect. The percentage error was high, confirming previous studies [11,35]. The BlandAltman analysis did not provide different results for $\mathrm{CI}_{\text {Starling-8.1 }}$ and $\mathrm{CI}_{\text {Starling-24.4. }}$ On the contrary, the trending ability of the device was much better. In particular, the polar plot analysis of changes provided acceptable results. Interestingly, when changes were assessed during EEXPO, the trending ability of $\mathrm{CI}_{\text {Starling-8.1 }}$ was better than that of $\mathrm{CI}_{\text {Starling-24.4, }}$ confirming that these shortterm changes were better tracked by the former version than by the latter.

Of note, the present study also contributes to the validation of the EEXPO test. The EEXPO-induced $\triangle \mathrm{CI}$ measured by pulse contour analysis well detected preload responsiveness, which was estimated through the PLRinduced $\triangle \mathrm{CI}$. The AUROC was above 0.900, a level achieved only by very reliable tests and indices of preload responsiveness [24, 36]. The fact that these results were obtained in patients ventilated with a $V t \leq 6 \mathrm{~mL} / \mathrm{kg}$ confirms that low Vt ventilation does not make the EEXPO test unreliable, despite studies affirming the contrary [37, 38]. In addition, it confirms that in the presence of low Vt, the reliability of both PPV and SVV is limited: as shown in Table 2, no significant differences were observed between preload responders and non-responders. Of note, a limitation of the EEXPO test is that the patients must be able to sustain a rather long ventilator occlusion. In the present study, the Richmond Agitation Sedation Scale score was quite high.

\section{Limitations}

First, we defined preload responsiveness by a positive PLR test and a fluid bolus was not infused in all the patients. However, the demonstration of PLR test reliability is likely strong enough today to allow one to consider it as a reliable surrogate of a fluid bolus [24]. Second, we investigated only a 15-s EEXPO test; a duration of $30 \mathrm{~s}$ has also been described [34]. With a longer EEXPO, the performances of $\mathrm{CI}_{\text {Starling-8.1 }}$ and $\mathrm{CI}_{\text {Starling-24.4 }}$ in tracking $\triangle \mathrm{CI}$ might have differed less. Third, we included only hemodynamically stable patients who did not require changes in vasopressor dosage: we cannot, therefore, address the issue of whether the reliability of bioreactance could be influenced by short-term changes in afterload. In addition, sepsis was the cause of circulatory failure in most of the patients (86\%). Thus, in theory, our results should apply only to this specific population. Finally, we investigated only ICU patients, though the best reliability of bioreactance has been demonstrated in normal subjects $[39,40]$ or in the peri-operative setting $[8,9]$.

\section{Conclusion}

The Starling bioreactance device reliably detects preload responsiveness through the EEXPO test, provided that its averaging time is reduced to $8 \mathrm{~s}$ and its refresh time to one second.

\section{Abbreviations \\ AUROC: Area under the receiver operating characteristic curve; $\mathrm{Cl}$ : Cardiac index; $\mathrm{Cl}_{\text {Starling-24.4: }}$ Cardiac index measured by the commercial version of the Starling device (averaging time 24 seconds, refresh time 4 seconds); $\mathrm{Cl}_{\text {Starling-8.1: }}$ Cardiac index derived through raw data analysis of the Starling device (averag- ing time 8 seconds, refresh time 1 second); $\mathrm{Cl}_{\text {pulse }}$ : Cardiac index measured by the pulse contour analysis method; EEXPO: End-expiratory occlusion.; ICC: Intraclass correlation coefficient; ICU: Intensive care unit.; PLR: Passive leg rais- ing; $\vee \mathrm{t}$ : Tidal volume; $\triangle \mathrm{Cl}$ : Changes in cardiac index.}

\section{Supplementary Information}

The online version contains supplementary material available at https://doi. org/10.1186/s13613-021-00920-7.

Additional file 1. Additional tables and figures

\section{Acknowledgements}

Not applicable.

\section{Authors' contributions}

FG acquired the data, performed data analysis and interpretation and wrote the manuscript. $A B$ acquired the data and contributed to data analysis. J-LT designed the study, participated in data analysis and interpretation and contributed to writing the manuscript. NDV acquired the data and contributed to data analysis. DA performed data analysis and interpretation and contributed to writing the manuscript. RS acquired the data. AP acquired the data. XM designed the study, performed data analysis and interpretation and wrote the manuscript. All authors read and approved the final manuscript.

\section{Funding}

No funding.

Availability of data and materials

Individual, de-identified participant data are available from the corresponding author on reasonable request.

\section{Declarations}

Ethics approval and consent to participate

Information and consent obtained for each patient. Name of the ethics committee that approved the study and the committee's reference number: Comité pour la Protection des Personnes Ile-de-France IX. Trial registration 
IDRCB: 2018-A02825-50. Registered 13 December 2018. The patients were included prospectively.

\section{Consent for publication}

Not applicable.

\section{Competing Interests}

J-LT and XM are members of the medical advisory board for Pulsion Medical Systems. J-LT and XM gave lectures for Baxter. The other authors have no conflicts of interest to declare.

\section{Author details}

'Service de Médecine Intensive-Réanimation, Université Paris-Saclay, AP-HP, Hôpital de Bicêtre, DMU CORREVE, Inserm UMR S_999, FHU SEPSIS, CARMAS, 78, Rue du Général Leclerc, 94270 Le Kremlin-Bicêtre, France. ${ }^{2}$ Emergency Medicine Unit, Department of Translational Medicine, Università degli Studi del Piemonte Orientale, 28100 Novara, Italy. ${ }^{3}$ Research Support Unit, Department of Translational Medicine, Università degli Studi del Piemonte Orientale, 28100 Novara, Italy.

Received: 26 April 2021 Accepted: 16 August 2021

Published online: 28 August 2021

\section{References}

1. Teboul J-L, Saugel B, Cecconi M, De Backer D, Hofer CK, Monnet X, et al. Less invasive hemodynamic monitoring in critically ill patients. Intensive Care Med. 2016;42:1350-9.

2. Beurton A, Teboul J-L, Gavelli F, Gonzalez FA, Girotto V, Galarza L, et al. The effects of passive leg raising may be detected by the plethysmographic oxygen saturation signal in critically ill patients. Crit Care. 2019;23:19.

3. Ameloot K, Palmers P-J, Malbrain MLNG. The accuracy of noninvasive cardiac output and pressure measurements with finger cuff: a concise review. Curr Opin Crit Care. 2015:21:232-9.

4. Wagner JY, Sarwari H, Schön G, Kubik M, Kluge S, Reichenspurner H, et al. Radial artery applanation tonometry for continuous noninvasive cardiac output measurement: a comparison with intermittent pulmonary artery thermodilution in patients after cardiothoracic surgery. Crit Care Med. 2015;43:1423-8.

5. Monnet X, Bataille A, Magalhaes E, Barrois J, Le Corre M, Gosset C, et al. End-tidal carbon dioxide is better than arterial pressure for predicting volume responsiveness by the passive leg raising test. Intensive Care Med. 2013;39:93-100.

6. Saugel B, Vincent J-L. Cardiac output monitoring: how to choose the optimal method for the individual patient. Curr Opin Crit Care. 2018;24:165-72.

7. Keren H, Burkhoff D, Squara P. Evaluation of a noninvasive continuous cardiac output monitoring system based on thoracic bioreactance. Am J Physiol Heart Circ Physiol. 2007;293:H583-589.

8. Marqué S, Cariou A, Chiche J-D, Squara P. Comparison between FlotracVigileo and Bioreactance, a totally noninvasive method for cardiac output monitoring. Crit Care. 2009;13:R73.

9. Cheung H, Dong Q, Dong R, Yu B. Correlation of cardiac output measured by non-invasive continuous cardiac output monitoring (NICOM) and thermodilution in patients undergoing off-pump coronary artery bypass surgery. J Anesth. 2015;29:416-20.

10. Kupersztych-Hagege E, Teboul J-L, Artigas A, Talbot A, Sabatier C, Richard $C$, et al. Bioreactance is not reliable for estimating cardiac output and the effects of passive leg raising in critically ill patients. Br J Anaesth. 2013;111:961-6.

11. Galarza L, Mercado P, Teboul J-L, Girotto V, Beurton A, Richard C, et al. Estimating the rapid haemodynamic effects of passive leg raising in critically ill patients using bioreactance. Br J Anaesth. 2018;121:567-73.

12. Gavelli F, Teboul J-L, Monnet X. The end-expiratory occlusion test: please, let me hold your breath! Crit Care. 2019;23:274

13. Monnet X, Osman D, Ridel C, Lamia B, Richard C, Teboul J-L. Predicting volume responsiveness by using the end-expiratory occlusion in mechanically ventilated intensive care unit patients. Crit Care Med. 2009;37:951-6.
14. Gavelli F, Shi R, Teboul J-L, Azzolina D, Monnet X. The end-expiratory occlusion test for detecting preload responsiveness: a systematic review and meta-analysis. Ann Intensive Care. 2020;10:65.

15. Beurton A, Teboul J-L, Girotto V, Galarza L, Anguel N, Richard C, et al. IntraAbdominal Hypertension Is Responsible for False Negatives to the Passive Leg Raising Test. Crit Care Med. 2019;47:e639-47.

16. Bossuyt PM, Reitsma JB, Bruns DE, Gatsonis CA, Glasziou PP, Irwig L, et al. STARD 2015: an updated list of essential items for reporting diagnostic accuracy studies. BMJ. 2015;351:h5527.

17. Saugel $B$, Cecconi M, Hajjar LA. Noninvasive cardiac output monitoring in cardiothoracic surgery patients: available methods and future directions. J Cardiothorac Vasc Anesth. 2019;33:1742-52.

18. Jozwiak M, Monnet $X$, Teboul J-L. Less or more hemodynamic monitoring in critically ill patients. Curr Opin Crit Care. 2018;24:309-15.

19. Monnet X, Persichini R, Ktari M, Jozwiak M, Richard C, Teboul J-L. Precision of the transpulmonary thermodilution measurements. Crit Care. 2011;15:R204.

20. Monnet X, Teboul J-L. Transpulmonary thermodilution: advantages and limits. Crit Care. 2017;21:147.

21. Jozwiak M, Monnet $X$, Teboul J-L. Pressure waveform analysis. Anesth Analg. 2018;126:1930-3.

22. Kirkpatrick AW, Roberts DJ, De Waele J, Jaeschke R, Malbrain MLNG, De Keulenaer B, et al. Intra-abdominal hypertension and the abdominal compartment syndrome: updated consensus definitions and clinical practice guidelines from the World Society of the Abdominal Compartment Syndrome. Intensive Care Med. 2013;39:1190-206.

23. Monnet $X$, Teboul J-L. Passive leg raising: five rules, not a drop of fluid! Crit Care. 2015;19:18.

24. Monnet X, Marik P, Teboul J-L. Passive leg raising for predicting fluid responsiveness: a systematic review and meta-analysis. Intensive Care Med. 2016;42:1935-47.

25. de Courson H, Ferrer L, Cane G, Verchère E, Sesay M, Nouette-Gaulain K, et al. Evaluation of least significant changes of pulse contour analysisderived parameters. Ann Intensive Care. 2019;9:116.

26. Holm S. A simple sequentially rejective multiple test procedure. Scand J Stat. 1979;6:65-70.

27. Hanley JA, MCNeil BJ. A method of comparing the areas under receiver operating characteristic curves derived from the same cases. Radiology. 1983;148:839-43.

28. Taffé P, Peng M, Stagg V, Williamson T. MethodCompare: an R package to assess bias and precision in method comparison studies. Stat Methods Med Res. 2019;28:2557-65.

29. Critchley LA, Yang XX, Lee A. Assessment of trending ability of cardiac output monitors by polar plot methodology. J Cardiothorac Vasc Anesth. 2011;25:536-46.

30. R Development Core Team. R: a language and environment for statistical computing. Vienna: R Foundation for Statistical Computing; 2008.

31. Monnet $X$, Teboul J-L. Assessment of fluid responsiveness: recent advances. Curr Opin Crit Care. 2018;24:190-5.

32. Biais M, de Courson H, Lanchon R, Pereira B, Bardonneau G, Griton M, et al. Mini-fluid Challenge of $100 \mathrm{ml}$ of Crystalloid Predicts Fluid Responsiveness in the Operating Room. Anesthesiology. 2017;127:450-6.

33. Georges D, de Courson H, Lanchon R, Sesay M, Nouette-Gaulain K, Biais M. End-expiratory occlusion maneuver to predict fluid responsiveness in the intensive care unit: an echocardiographic study. Crit Care. 2018;22:32.

34. Biais M, Larghi M, Henriot J, de Courson H, Sesay M, Nouette-Gaulain K. End-Expiratory Occlusion Test Predicts Fluid Responsiveness in Patients With Protective Ventilation in the Operating Room. Anesth Analg. 2017;125:1889-95.

35. Lamia B, Kim HK, Severyn DA, Pinsky MR. Cross-comparisons of trending accuracies of continuous cardiac-output measurements: pulse contour analysis, bioreactance, and pulmonary-artery catheter. J Clin Monit Comput. 2018;32:33-43.

36. Yang X, Du B. Does pulse pressure variation predict fluid responsiveness in critically ill patients? A systematic review and meta-analysis. Crit Care. 2014;18:650.

37. Jozwiak M, Depret F, Teboul J-L, Alphonsine J-E, Lai C, Richard C, et al. Predicting fluid responsiveness in critically III patients by using combined end-expiratory and end-inspiratory occlusions with echocardiography. Crit Care Med. 2017;45:e1131-8. 
38. Dépret F, Jozwiak M, Teboul J-L, Alphonsine J-E, Richard C, Monnet X. Esophageal doppler can predict fluid responsiveness through end-expiratory and end-inspiratory occlusion tests. Crit Care Med. 2019;47:e96-102.

39. Elliott A, Hull JH, Nunan D, Jakovljevic DG, Brodie D, Ansley L. Application of bioreactance for cardiac output assessment during exercise in healthy individuals. Eur J Appl Physiol. 2010;109:945-51.
40. Jones TW, Houghton D, Cassidy S, MacGowan GA, Trenell MI, Jakovljevic DG. Bioreactance is a reliable method for estimating cardiac output at rest and during exercise. Br J Anaesth. 2015;115:386-91.

\section{Publisher's Note}

Springer Nature remains neutral with regard to jurisdictional claims in published maps and institutional affiliations.
Submit your manuscript to a SpringerOpen ${ }^{\odot}$ journal and benefit from:

- Convenient online submission

- Rigorous peer review

- Open access: articles freely available online

- High visibility within the field

- Retaining the copyright to your article

Submit your next manuscript at $\boldsymbol{\nabla}$ springeropen.com 